\title{
Shape selectivity through entropy
}

\author{
Merijn Schenk, ${ }^{\mathrm{a}}$ Sofia Calero, ${ }^{\mathrm{a}}$ Theo L.M. Maesen, ${ }^{\mathrm{b}, *}$ Thijs J.H. Vlugt, ${ }^{\mathrm{c}}$ Lucas L. van Benthem, ${ }^{\mathrm{a}}$ \\ Martijn G. Verbeek, ${ }^{\mathrm{a}}$ Benoit Schnell, ${ }^{\mathrm{a}}$ and Berend Smit ${ }^{\mathrm{a}}$ \\ ${ }^{a}$ Department of Chemical Engineering, University of Amsterdam, Nieuwe Achtergracht 166, 1018 WV, Amsterdam, The Netherlands \\ ${ }^{\mathrm{b}}$ ChevronTexaco, Energy Research and Technology Company, 100 Chevron Way, 10-1412, Richmond, CA 94802-0627, USA \\ ${ }^{c}$ Instituut-Lorentz for Theoretical Physics, PO Box 9506, 2300 RA Leiden, The Netherlands
}

Received 6 June 2002; revised 2 October 2002; accepted 17 October 2002

\begin{abstract}
Based on a comparison between measured and simulated adsorption properties, we demonstrate that a decrease in the Gibbs free energy of formation and adsorption-due to higher adsorption entropy—satisfactorily explains the selective production and adsorption of the most compact, branched paraffins in $n$-hexadecane hydroconversion in molecular sieves with pore diameters of $\sim 0.75 \mathrm{~nm}$. Adsorption entropy is important because the pores are saturated with reactant, and because the adsorbed phase is not at gas-phase chemical equilibrium. This explanation supplants the traditional kinetic explanation involving changes in the Gibbs free energy of formation of the relevant transition states. Instead, we attribute the effect of molecular sieve structure on the branched paraffin yield to a redirection of the hydroisomerization reactions away from the gas-phase chemical equilibrium distribution, commensurate with the Gibbs free energy of adsorption of the isomers inside the pores. These shape-selective changes to the reaction rates appear to be as ubiquitous as those originating from steric constraints imposed on intracrystalline diffusion and reaction rates. This would make adsorption-induced changes in the Gibbs free energy of formation of reactants, intermediates, and products a missing cornerstone in traditional shape selectivity theory.
\end{abstract}

(C) 2003 Elsevier Science (USA). All rights reserved.

Keywords: Paraffins; Hydrocarbon conversion; Molecular modeling; Shape selectivity; Zeolites; Adsorption entropy

\section{Introduction}

Molecular sieves with three-dimensional framework structures find many applications in catalysis [1-3]. In order to fully utilize the structural diversity afforded by the panoply of available molecular sieve structures [4] we need a fundamental understanding of the link between structure and shape selectivity. Traditional theory says that the structures induce shape selective conversion by imposing steric constraints on the reaction (transition-state shape selectivity) and on the diffusion rate (product and reactant shape selectivity) [5-7]. However, this explanation alone is not sufficient to understand shape selectivity [8-13]. A number of additional parameters (such as inverse shape selectivity) have been proposed [5,11-15], but these have remained subject to debate $[5,16-20]$.

In a recent attempt to come up with a more systematic approach to shape selectivity we suggested that molecular

\footnotetext{
* Corresponding author.

E-mail address: tmaesen@chevrontexaco.com (T.L.M. Maesen).
}

sieves impose a chemical equilibrium on adsorbed molecules that is different from that in the gas phase [17,21-24]. In sieves with relatively small pores, and, therefore, predominantly molecule-wall interactions, the imposed chemical equilibrium could be successfully ascertained by simulations at low loading $[17,21]$. However, for sieves with larger pores, the effects of intermolecular interactions at higher loading may need to be considered [24]. One of the aims of this work is to investigate whether adsorbent-adsorbent interactions contribute to the selectivity. Irrespective of the specific interactions involved, the Gibbs free energy of adsorption quantifies how a molecular sieve structure and the other adsorbed molecules alter the gas-phase Gibbs free energy of formation of a hydrocarbon. By definition, the Gibbs free energy of adsorption is the difference of the Gibbs free energy formation in the gas phase and that in the adsorbed phase. Naturally, adsorption can only yield a chemical equilibrium different from that in the gas phase as long as the molecular exchange between the adsorbed phase and gas phase is sufficiently slow so as to prevent physical equilibration be- 


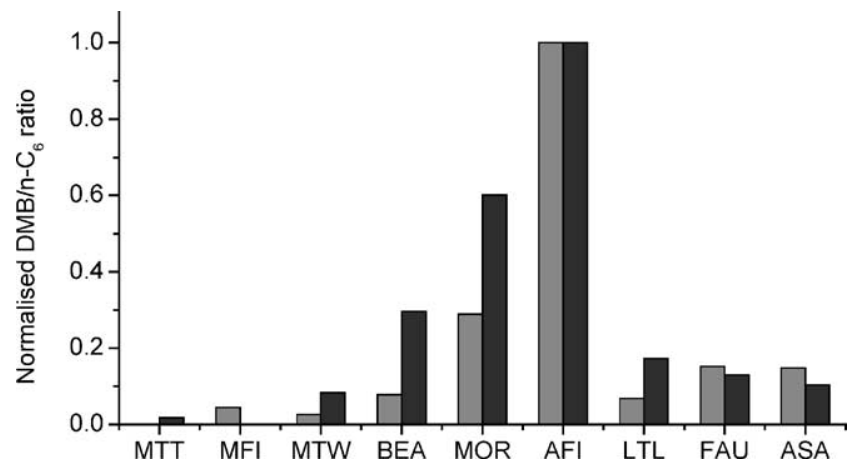

Fig. 1. Molar ratio of $22 \mathrm{DMB} / n-\mathrm{C}_{6}$ adsorbed (left, light gray bar) and of ratio $\mathrm{DMB} / n-\mathrm{C}_{6 c a t a l}$ produced (right, dark gray bar) by $n-\mathrm{C}_{16}$ hydroconversion at $70 \% \mathrm{C}_{16}$ hydrocracking, $577 \mathrm{~K}, 3 \times 10^{3} \mathrm{kPa} n-\mathrm{C}_{16}$. All catalysts were made equally active by adding nitrogen-containing compound to the feed. Molar ratios were normalized relative to the ratios of AFI-type sieves. The pore diameter increases from the MTT-type zeolite to the amorphous aluminosilicate (ASA). Data adapted from Ref. [10].

tween the two phases $[22,23]$. This tends to be the case at high loading [21-23,25,26].

Recent simulations indicate that molecular sieves skew the chemical equilibrium, favoring molecules whose shape is commensurate with that of the pores [17,21]. That being the case, the snug fit between adsorbate and adsorbent assures that the molecules remain essentially trapped, and that they can only be detected by their consecutive reaction products, which fit less well, and so diffuse out [17,21,27,28]. Interestingly, earlier work by Santilli and co-workers had suggested that there are also molecular sieves that both preferentially adsorb and release the best fitting molecules. Thus AFI-type pores would yield predominantly the most snugly fitting, branched paraffins in $n$-hexadecane $\left(n-\mathrm{C}_{16}\right)$ hydroconversion [8-10]. This phenomenon was referred to as "inverse shape selectivity" [8-10]. In that instance, the thermodynamic preference for branched paraffins was quantified by physically equilibrating an equimolar gaseous mixture of di-, mono, and nonbranched hexane $\left(\mathrm{C}_{6}\right)$ isomers on molecular sieves with various structures [8-10]. The relative preference of various structures for adsorbing branched paraffins appeared to translate into a preference for their formation in hydrocarbon hydroconversion (Fig. 1) [8-10,29].

Simulations (using molecular "docking") were then employed to try and understand, at the molecular level, why the selective adsorption of branched rather than linear paraffins would lead to their selective production. These simulations suggested that the variations in adsorption enthalpy related to pore size and could explain the experimental data. The 0.70-0.74-nm pores (as in AFI-type zeolites) would have optimal stabilizing Van der Waals interactions with the branched paraffins, and, therefore, a minimal adsorption enthalpy [10]. Inside smaller pores (like MTW-type zeolites) the adsorption enthalpy would increase, because the walls would repulse branched paraffins. Inside larger pores (as in FAU-type zeolites), the stabilizing interaction would disappear, because these pores would be so large that adsorbate-adsorbent Van der Waals interactions become negligible [10]. Assuming that this variation in adsorption enthalpy with pore size could be extrapolated to the variation of the Gibbs free energy of the transition state for the formation of branched molecules, the inverse shape selectivity phenomenon was categorized as an example of transitionstate selectivity $[9,10]$. This represents some of the earliest work to employ molecular simulations to explain, and even predict, the catalytic properties of molecular sieves based on their adsorption properties.

The molecular "docking" technique enabled an evaluation of the adsorption enthalpy of paraffins at low loading by using a CVFF force field. It has since become apparent that the CVFF force field is not particularly suited for simulating the forces exerted on branched paraffins [30]. For example, the adsorption isotherms of isobutane by MFI-type silica show a step at approximately half the loading, such a step cannot be reproduced with this force field [30]. At the same time, the drastic improvement in computation capabilities has made it possible to simulate entropy and loading effects [31-33]. Recent configurational-bias Monte Carlo (CBMC) simulations showed how differences in configurational adsorption entropy (packing efficiency) dominated the adsorption in $\sim 0.55$-nm MFI-type pores from ternary mixtures of $\mathrm{C}_{6}$ isomers with various degrees of branching, at high loading [31-33].

The initial motivation of this work was to redo the calculations of Santilli et al. [10] using modern simulation techniques and using contemporary force fields. As we will demonstrate, these improved calculations did not yield an improvement in the prediction of the shape selectivity. In fact, our calculations predict that all large-pore zeolites would give a similar product distribution, which is in disagreement with the experimental data. This suggests that the simulation results of Santilli et al. may have resulted from a cancellation of the errors in the force field and the limitation of the simulation method, which did not allow simulations at conditions approaching the actual reaction conditions. More importantly, our results also suggest that the molecular interpretation of Santilli et al. that inverse shape selectivity can be related to a match of the size of a branched molecule with the diameter of the channel may not be correct. Here, we will demonstrate that the molecular basis of inverse shape selectivity is related to entropic effects inside the zeolite pores under conditions where the zeolites are (almost) fully saturated.

This paper focuses on molecular sieves with a pore diameter greater than $0.60 \mathrm{~nm}$. Those with an AFI-type structure receive the most attention, because the majority of the measured data happen to be available for this type of sieve [8-10,29,34-38]. 


\section{Molecular simulation methods}

To study the driving forces behind the adsorption selectivity and the hydroconversion selectivity of various zeolites, one needs detailed information on a molecular level about adsorbed hydrocarbons. We obtain this information by using computer simulations based on the configurational-bias Monte Carlo technique.

The configurational-bias Monte Carlo technique affords a relatively efficient calculation of the thermodynamic properties and adsorption isotherms of hydrocarbons in microporous silica structures $[16,17,21,31,33]$. In the CBMC scheme the molecules are grown atom by atom in such a way that the empty channels inside the zeolite are found. This results in a sampling scheme that is orders of magnitude more efficient than traditional Monte Carlo schemes, where entire molecules are inserted at once, generating a high percentage of unlikely or impossible configurations in the process. Because of its efficiency, the CBMC scheme allows us to obtain information about hydrocarbons as large as hexadecane $\left(\mathrm{C}_{16}\right)$.

The CBMC simulations model uses single interaction centers (united atoms) to represent the $\mathrm{CH}_{3}, \mathrm{CH}_{2}$, and $\mathrm{CH}$ groups in the linear and branched paraffins. The bonded interactions include bond-bending and torsion potentials. Dispersive interactions with the oxygen atoms of the silica structure are assumed to dominate the silica-paraffin interactions. The zeolite is modeled as a rigid crystal [39] consisting exclusively of $\mathrm{SiO}_{2}$, so as to make the calculation of paraffinzeolite interactions efficient. This allows the use of special interpolation techniques $[40,41]$ to obtain the correct paraffin conformation at any given temperature. More details about the simulation method and the force fields are described elsewhere [31]. The sizes of the molecules and the energy parameters have been fitted to the adsorption enthalpies and the Henry coefficients of linear and monobranched paraffins in aluminum-free MFI-type silicas [31]. The resultant force field reproduces the Henry coefficients, the changes in the free energy of formation (i.e., the free energy of adsorption), the adsorption enthalpies, and isotherms for linear and monobranched paraffins. The same force field also reproduces these parameters remarkably well for microporous silica topologies other than the MFI type [16,42].

To obtain thermodynamic properties of individual isomers, a simulation in a system is used with a single molecule $(\mathrm{N})$ in an infinite zeolite $(\mathrm{V})$ at a fixed temperature $(\mathrm{T})$ (so called "NVT ensemble").

The NVT simulations consist of four different trial moves:

(1) Displacement of a chain: a chain is selected at random and given a random displacement. The maximum displacement was taken such that $50 \%$ of the moves were accepted.

(2) Rotation of a chain: a chain is selected at random and given a random rotation around the center of mass. The maximum rotation angle was selected such that $50 \%$ of the moves were accepted.

(3) Partial regrowth of the chain: a randomly selected part of a randomly selected alkane is regrown.

(4) Complete regrowth of the chain: a chain is selected at random and is completely regrown at a randomly selected position. During this step data are collected from which the Henry coefficient and the free energy are determined.

The calculation of an adsorption isotherm of a mixture of alkanes requires a simulation in the grand-canonical ensemble [31]. Such a simulation employs the same initial three steps as one in the NVT ensemble, but the fourth step is replaced by:

(4) Exchange with the reservoir: an alkane is randomly added or removed from the microporous silica structure.

(5) Identity change: an attempt is made to change the isomer type of a randomly selected molecule.

The relative probabilities for attempting these moves in an NVT simulation were such that $10 \%$ of the total number of moves was a displacement, $10 \%$ a rotation, $10 \%$ a partial regrowth, and $70 \%$ a regrowth of the entire molecule. A simulation consists of $5 \times 10^{6}$ Monte Carlo moves. In the grand-canonical simulations the probabilities were $15 \%$ displacement, $15 \%$ rotation, $15 \%$ partial regrowth, $50 \%$, exchange, and $5 \%$ identity change. A typical simulation requires some $10^{7}$ Monte Carlo moves. The calculation of the change in the free energy of formation, the Henry coefficient, and the adsorption enthalpy at zero coverage requires two simulations in the NVT ensemble: one simulation of a single paraffin inside the micropores of silica structure and another simulation in the ideal gas situation [31].

The atomic coordinates for the silica structures identified by a three-letter code were adapted from the compilations published by the Structure Commission of the International Zeolite Association [4]. For SSZ-31 the coordinates describing polymorph A were chosen [43].

Since the Helmholtz and Gibbs free energies converge at low loading, both relate to the Henry coefficient, $K_{\mathrm{H}}(\mathrm{mol} /$ $\mathrm{kg} \mathrm{Pa}$ ) by [41]

$\Delta G=-R T \ln \left(K_{\mathrm{H}} D R T\right)$.

In this formula $\Delta G(\mathrm{~J} / \mathrm{mol})$ is the free energy of adsorption, $D\left(\mathrm{~kg} / \mathrm{m}^{3}\right)$ is the framework density of a structure, $R$ is the gas constant (viz. $8.3144 \mathrm{~J} / \mathrm{mol} \mathrm{K}$ ), and $T(\mathrm{~K})$ the temperature. Measured adsorption data were recalculated using formula (1) instead of a relationship with an arbitrarily defined standard state (as was used in Refs. [35,37,44]).

From the simulated adsorption enthalpy, $\Delta H(\mathrm{~J} / \mathrm{mol})$, and the Gibbs free energy, the adsorption entropy, $\Delta S$ $(\mathrm{J} / \mathrm{mol} \mathrm{K})$ can be calculated using

$\Delta G=\Delta H-T \Delta S$. 
At extremely low loading and at $533 \mathrm{~K}$, the difference in adsorption enthalpy between 2,2-dimethylbutane (22DMB) and $n$-hexane $\left(n-\mathrm{C}_{6}\right) \delta \Delta H_{\mathrm{CMBC}}$ was defined as the difference between the adsorption enthalpies of the individual components as determined by CBMC simulations, $\Delta H_{22 \mathrm{DMB}}(\mathrm{J} / \mathrm{mol})$ and $\Delta H_{n-\mathrm{C} 6}(\mathrm{~J} / \mathrm{mol})$, respectively,

$\delta \Delta H_{\mathrm{CBMC}}=\Delta H_{22 \mathrm{DMB}}-\Delta H_{n-\mathrm{C} 6}$.

Similarly, the difference in the Gibbs free energy of adsorption of 22DMB and that of $n-\mathrm{C}_{6} \delta \Delta G_{\mathrm{CMBC}}(\mathrm{J} / \mathrm{mol})$ was determined from the Gibbs free energies of adsorption of the individual components:

$\delta \Delta G_{\mathrm{CBMC}}=\Delta G_{22 \mathrm{DMB}}-\Delta G_{n-\mathrm{C} 6}$.

The measured differences in Gibbs free energy of adsorption between $22 \mathrm{DMB}$ and $n-\mathrm{C}_{6}, \delta \Delta G_{\text {ads } 22-n}(\mathrm{~J} / \mathrm{mol})$, were calculated from the measured ratio between the loading of these two compounds, [22DMB] and $\left[n-\mathrm{C}_{6}\right]$ in $(\mathrm{mg} / \mathrm{g})$, respectively,

$\delta \Delta G_{\mathrm{ads} 22-n}=-R T \ln \left([22 \mathrm{DMB}] /\left[n-\mathrm{C}_{6}\right]\right)$.

In this formula $T$ is the temperature at which the hexane $\left(\mathrm{C}_{6}\right)$ isomers were adsorbed $(403 \mathrm{~K})$. The same $-R T \ln ([22$ $\left.\mathrm{DMB}] /\left[n-\mathrm{C}_{6}\right]\right)$ term was also used to calculate the Gibbs free energy difference at $14 \mathrm{kPa}, \delta \Delta G_{14} \mathrm{kPa} 22-n(\mathrm{~J} / \mathrm{mol})$, and at $500 \mathrm{kPa}, \delta \Delta G_{500 \mathrm{kPa} 22-n}(\mathrm{~J} / \mathrm{mol})$, from simulated binary isotherms at $403 \mathrm{~K}$ with equal amounts of $22 \mathrm{DMB}$ and $n-\mathrm{C}_{6}$. It was also used in Ref. [10] to try and relate the differences in adsorption enthalpy between adsorbed 22DMB and $n-\mathrm{C}_{6}$ as obtained in a CVFF force field at $423 \mathrm{~K}, \delta \Delta H_{\mathrm{CVFF}}$ $(\mathrm{J} / \mathrm{mol})$. An analogous formula was used to calculate the difference in Gibbs free energy of adsorption from a simulated binary isotherm with equal amounts of 2,3-dimethylbutane (23DMB) and $n-\mathrm{C} 6$ at $500 \mathrm{kPa} \delta \Delta G_{500 \mathrm{kPa} 23-n}(\mathrm{~J} / \mathrm{mol})$. A value assumed to be proportional to the difference in Gibbs free energy of formation, $\delta \Delta G_{\text {catal }}(\mathrm{J} / \mathrm{mol})$, between either dimethyltetradecanes $\left(\mathrm{dM}-\mathrm{C}_{14}\right)$ and tetramethyldodecanes (teM- $\mathrm{C}_{12}$ ) or DMB and $n-\mathrm{C}_{6}$ inside the various sieves, at $70 \% \mathrm{C}_{16}$ hydrocracking and $577 \pm 12 \mathrm{~K}$ [10] was calculated using

$\delta \Delta G_{\text {catal }}=-R T \ln \left(\mathrm{DMB} / n-\mathrm{C}_{6}\right)$.

In this formula (DMB) and $\left(n-\mathrm{C}_{6}\right)$ represent the concentration of $\mathrm{DMB}$ and $n-\mathrm{C}_{6}$ in the product slate from $n$ hexadecane $\left(n-\mathrm{C}_{16}\right)$ hydroconversion. The DMB fraction always consisted for more than $90 \%$ of 23DMB [10].

In our simulations we impose the temperature and the chemical potential (or fugacities) on the components. Experimentally, the adsorption isotherms are expressed in loading versus partial pressure (instead of fugacity, as we do in our simulations). We have converted the fugacities into pressures assuming ideal gas behavior, which is a reasonable approximation under the conditions studied in this work. Of course, the exact conversion can be made using the experimental equations of state.

\section{Results and discussion}

\subsection{Adsorption at low loading}

In trying to explain the measured adsorption phenomena by molecular simulations, Santilli et al. were hamstrung by the computational limitations of the early 1990s. Because of these limitations, it was expedient to assume that the loading was sufficiently low for intermolecular interactions to be negligible [10], and that differences in adsorption entropy between $\mathrm{C}_{6}$ isomers were negligible [10]. With these assumptions in place, a good correlation between the difference in Gibbs free energy of adsorption determined from the measured ternary isotherms and the difference in adsorption enthalpy obtained in the CVFF force field, $\delta \Delta H_{\mathrm{CVFF}}$ $(\mathrm{kJ} / \mathrm{mol})$, was found [10]. This correlation suggests that the explanation for both the preferential adsorption and the preferential production of branched paraffins lies in the variation in adsorption enthalpy with void size [10]. Since the adsorbent-adsorbate Van der Waals interactions have a major effect on the adsorption enthalpy, these were assumed to be the dominant force in both the adsorption and the catalytic production of DMB [10].

The differences in adsorption enthalpy between 22DMB and $n-\mathrm{C}_{6}, \delta \Delta H_{\mathrm{CBMC}}(\mathrm{kJ} / \mathrm{mol})$ simulated by CBMC at low loading, do not match the enthalpy differences obtained in the CVFF force field (Table 1). This probably reflects the currently known limitations of the CVFF force field in handling branched paraffins [30]. Consistent with earlier validations [16,31-33,42], the adsorption enthalpies from the CBMC calculations agree well with the adsorption enthalpies measured using only a single component at low loading (Table 2) [35,36,44-47]. The relatively large differences between simulated and measured adsorption enthalpy for FAU-type zeolites (Table 2) suggests that a perfect FAU-type silica structure is not an ideal model for the experimentally used FAU-type zeolites that include nonframework debris left inside their pores by steaming. The good match between simulated and measured adsorption enthalpy for sieves other than FAU-type zeolites indicates that perfect silica structures are a good representation of the other sieves.

Considering the good match between the CBMC-simulated and the measured adsorption enthalpies at low loading, it is surprising that the CBMC-simulated adsorption data do not reproduce the measured preference for adsorbing 22DMB rather than $n-\mathrm{C}_{6}$ (Table 1 ). Most notably, the CBMC simulations reproduce neither the lower Gibbs free energy of adsorption nor the lower adsorption enthalpy of branched paraffins as compared to normal paraffins in AFItype sieves (Table 1). Instead, the adsorption enthalpies of branched 22DMB and linear $n-\mathrm{C}_{6}$ are similar and decrease steadily with pore size, until repulsive interactions with the pore walls increase the adsorption enthalpy of 22DMB relative to that of $n-\mathrm{C}_{6}$ (Fig. 2). This is at approximately $0.65 \mathrm{~nm}$ as represented by OFF-, CON-, and MOR-type 
Table 1

The difference in Gibbs free energy of adsorption between 22DMB and $n-\mathrm{C}_{6}$ (a) determined from a measured ternary isotherm of an equimolar mixture of 22DMB, 3MP, and $n-\mathrm{C}_{6}$ at $14 \mathrm{kPa} \mathrm{C} 6,403 \mathrm{~K}, \delta \Delta G_{\text {ads } 22-n}(\mathrm{~kJ} / \mathrm{mol})$, (b) determined from a simulated binary isotherm with equal amounts of $22 \mathrm{DMB}$ and $n-\mathrm{C}_{6}$ at $14 \mathrm{kPa} \mathrm{C}_{6}, 403 \mathrm{~K}, \delta \Delta G_{14 \mathrm{kPa} 22-n}(\mathrm{~kJ} / \mathrm{mol})$, and (c) determined at very low loading, $\delta \Delta G_{\mathrm{CBMC}}(\mathrm{kJ} / \mathrm{mol})$

\begin{tabular}{|c|c|c|c|c|c|c|}
\hline $\begin{array}{c}\text { Structure } \\
\text { type } \\
\text { code }\end{array}$ & $\begin{array}{l}\text { Pore } \\
\text { size } \\
(\mathrm{nm})\end{array}$ & $\begin{array}{c}\delta \Delta G_{\text {ads } 22-n} \\
22 \mathrm{DMB}-n-\mathrm{C}_{6} \\
(\mathrm{~kJ} / \mathrm{mol})\end{array}$ & $\begin{array}{c}\delta \Delta H_{\mathrm{CVFF}} \\
22 \mathrm{DMB}-n-\mathrm{C}_{6} \\
(\mathrm{~kJ} / \mathrm{mol})\end{array}$ & $\begin{array}{c}\delta \Delta H_{\mathrm{CBMC}} \\
22 \mathrm{DMB}-n-\mathrm{C}_{6} \\
(\mathrm{~kJ} / \mathrm{mol})\end{array}$ & $\begin{array}{c}\delta \Delta G_{\mathrm{CBMC}} \\
22 \mathrm{DMB}-n-\mathrm{C}_{6} \\
(\mathrm{~kJ} / \mathrm{mol})\end{array}$ & $\begin{array}{c}\delta \Delta G_{14 \mathrm{kPa} 22-n} \\
22 \mathrm{DMB}-n-\mathrm{C}_{6} \\
(\mathrm{~kJ} / \mathrm{mol})\end{array}$ \\
\hline$\overline{\text { FAU }}$ & 1.20 & 1.3 & n.a. ${ }^{b}$ & 1.6 & 0.3 & 2.1 \\
\hline LTL & 0.99 & 3.9 & 2.7 & 2.8 & 0.2 & 4.1 \\
\hline MAZ & 0.75 & n.a. & n.a. & 0.7 & -1.3 & -4.4 \\
\hline AFI & 0.77 & $-5.0--4.5$ & -5.1 & 1.1 & -0.9 & -4.7 \\
\hline MOR & 0.64 & -0.9 & n.a. & 5.1 & 5.4 & 0.9 \\
\hline BEA & 0.64 & 3.5 & n.a. & 8.3 & 10.1 & 5.8 \\
\hline MTW & 0.57 & 7.2 & 4.1 & 19.6 & 23.4 & 23.4 \\
\hline VFI & 1.27 & 2.7 & 0.0 & n.a. & n.a. & n.a. \\
\hline
\end{tabular}

$\delta \Delta H_{\mathrm{CVFF}}(\mathrm{kJ} / \mathrm{mol})$ and $\delta \Delta H_{\mathrm{CBMC}}(\mathrm{kJ} / \mathrm{mol})$ are the difference in adsorption enthalpy at very low loading determined by molecular "docking" in a CVFF force field and by $\mathrm{CBMC}$, respectively.

a Pore diameter from Ref. [10].

b n.a., not available.

silica (Fig. 2, Table 3). The repulsive interactions do not have much of an effect on the adsorption entropy until the fit with 22DMB becomes really tight (as in MTW, VET, SFE, Fig. 3, Table 3). As a result, the Gibbs free energies of both 22DMB and $n-\mathrm{C}_{6}$ decrease with pore size for as long as there are no repulsive interactions (until GME-, AFI-, CFI-sized pores, Fig. 4, Table 3). Once the walls start to repulse 22DMB (in OFF-, CON-, MOR-sized pores), the Gibbs free energy of adsorption of 22DMB increases significantly relative to that of $n$ - $\mathrm{C}_{6}$ (Fig. 4, Table 3). Thus, CBMC simulations suggest that 22DMB has a Gibbs free energy of adsorption that is either higher than or approximately equal to that of $n-\mathrm{C}_{6}$. As with the adsorption enthalpies, the CBMC-simulated Gibbs free energies calculated at low loading appear not to correlate with the Gibbs free energies of adsorption determined from the measured ternary isotherms (Table 1).

Table 2

Adsorption enthalpy for $n$ - $\mathrm{C}_{6}, 22 \mathrm{DMB}$, and 23DMB at low loading as obtained from CBMC simulations and from published measured data

\begin{tabular}{llccc}
\hline $\begin{array}{l}\text { Type } \\
\text { code }\end{array}$ & \multicolumn{1}{c}{ Source } & $\begin{array}{c}\Delta H_{n-\mathrm{C} 6} \\
(\mathrm{~kJ} / \mathrm{mol})\end{array}$ & $\begin{array}{c}\Delta H_{22 \mathrm{DMB}} \\
(\mathrm{kJ} / \mathrm{mol})\end{array}$ & $\begin{array}{c}\Delta H_{23 \mathrm{DMB}} \\
(\mathrm{kJ} / \mathrm{mol})\end{array}$ \\
\hline AFI & Simulated & -54 & -53 & -59 \\
AFI & Measured [35-37,46] & $-55--64$ & n.a. ${ }^{\mathrm{a}}$ & n.a. ${ }^{\mathrm{a}}$ \\
MOR & Simulated & -59 & -54 & -62 \\
MOR & Measured [37,44-47] & $-62--69$ & $-58^{\mathrm{b}}$ & $-59^{\mathrm{b}}$ \\
BEA & Simulated & -55 & -47 & -57 \\
BEA & Measured [44] & $-58^{\mathrm{b}}$ & $-50^{\mathrm{b}}$ & $-55^{\mathrm{b}}$ \\
MTW & Simulated & -70 & n.a. ${ }^{\mathrm{c}}$ & n.a. ${ }^{\mathrm{c}}$ \\
MTW & Measured [37] & $-70--75$ & n.a. ${ }^{\mathrm{c}}$ & n.a. \\
CON & Simulated & -58 & n.a. & n.a. ${ }^{\mathrm{c}}$ \\
CON & Measured [37] & $-60--65$ & n.a. ${ }^{\mathrm{c}}$ & n.a. ${ }^{\mathrm{c}}$ \\
FAU & Simulated & -33 & -31 & \\
FAU & Measured [44-46] & $-44--50$ & $-41^{\mathrm{b}}$ & $-42^{\mathrm{b}}$ \\
\hline
\end{tabular}

${ }^{a}$ The data in Ref. [38] were measured at too high a pressure to allow extrapolation to zero loading.

b Calculated with formula (1) from data provided in Ref. [44].

c Not available.

\subsection{Adsorption at high loading}

The incompatibility of simulated adsorption data at low loading and the adsorption data obtained from ternary isotherms suggests that the latter might not be at low loading. To evaluate this important assumption of Santilli et al., the measured ternary adsorption isotherm of an equimolar mixture of 22DMB, 3MP, and $n-\mathrm{C}_{6}$ by AFItype silica at $403 \mathrm{~K}$ was simulated to investigate the loading under experimental conditions. In view of the large variation in measured adsorption selectivity at high to intermediate loading [10,34], it matches the measured data quite reasonably (Fig. 5). The simulated isotherm indicates that the measured adsorption data at $14 \mathrm{kPa} \mathrm{C}_{6}$ were obtained at $\sim 56 \%$ of the saturation loading (Fig. 5). At such a high loading entropic effects due to intermolecular interactions tend to dominate the Gibbs free energy [31-33].

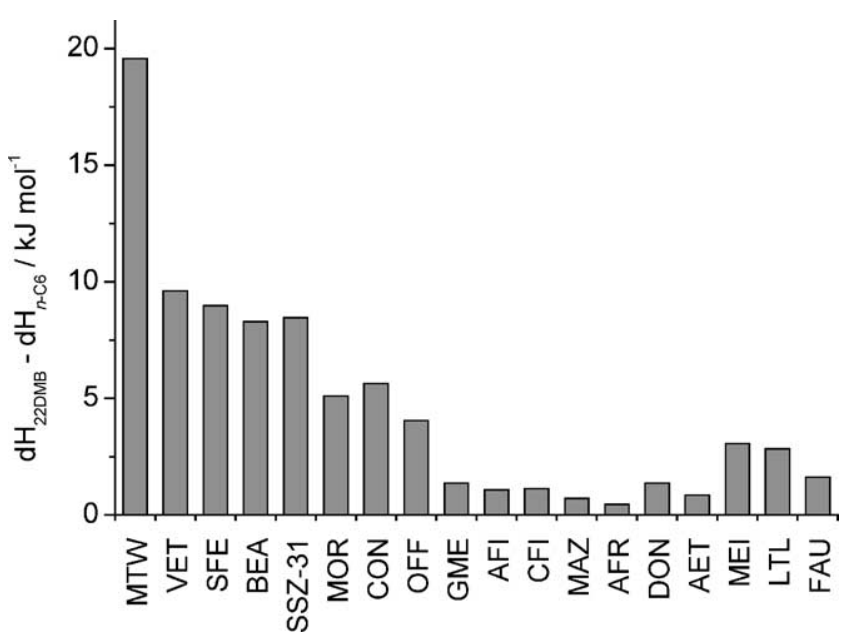

Fig. 2. Difference in adsorption enthalpy between 22DMB and $n-\mathrm{C}_{6}$ as calculated by CBMC. The structures are listed in order of increasing pore size. 
Table 3

Thermodynamic data on various structures calculated by $\mathrm{CBMC}$ at low loading, $533 \mathrm{~K}$ : the Gibbs free energy of adsorption ( $\Delta G_{n-\mathrm{C} 6}, \Delta G_{22 \mathrm{DMB}}, \Delta G_{23 \mathrm{DMB}}$ $(\mathrm{kJ} / \mathrm{mol}))$, the adsorption enthalpy $\left(\Delta H_{n-\mathrm{C} 6}, \Delta H_{22 \mathrm{DMB}}, \Delta H_{23 \mathrm{DMB}}(\mathrm{kJ} / \mathrm{mol})\right)$, and entropy $\left(\Delta S_{n-\mathrm{C} 6}, \Delta S_{22 \mathrm{DMB}}, \Delta S_{23 \mathrm{DMB}}(\mathrm{J} / \mathrm{mol} \mathrm{K})\right)$ for $n-\mathrm{C} 6$, for $22 \mathrm{DMB}$ and 23DMB, respectively

\begin{tabular}{|c|c|c|c|c|c|c|c|c|c|c|}
\hline $\begin{array}{l}\text { Type } \\
\text { code }\end{array}$ & $\begin{array}{c}\text { Pore size } \\
(\mathrm{nm})\end{array}$ & $\begin{array}{l}\Delta G_{n-\mathrm{C} 6} \\
(\mathrm{~kJ} / \mathrm{mol})\end{array}$ & $\begin{array}{c}\Delta H_{n-\mathrm{C} 6} \\
(\mathrm{~kJ} / \mathrm{mol})\end{array}$ & $\begin{array}{c}\Delta S_{n-\mathrm{C} 6} \\
(\mathrm{~J} / \mathrm{mol} \mathrm{K})\end{array}$ & $\begin{array}{c}\Delta G_{22 \mathrm{DMB}} \\
(\mathrm{kJ} / \mathrm{mol})\end{array}$ & $\begin{array}{c}\Delta H_{22 \mathrm{DMB}} \\
(\mathrm{kJ} / \mathrm{mol})\end{array}$ & $\begin{array}{l}\Delta S_{22 \mathrm{DMB}} \\
(\mathrm{J} / \mathrm{mol} \mathrm{K})\end{array}$ & $\begin{array}{c}\Delta G_{23 \mathrm{DMB}} \\
(\mathrm{kJ} / \mathrm{mol})\end{array}$ & $\begin{array}{c}\Delta H_{23 \mathrm{DMB}} \\
(\mathrm{kJ} / \mathrm{mol})\end{array}$ & $\begin{array}{l}\Delta S_{23 \mathrm{DMB}} \\
(\mathrm{J} / \mathrm{mol} \mathrm{K})\end{array}$ \\
\hline$\overline{\text { FAU }}$ & 1.20 & -14.5 & -33.1 & -35.0 & -14.2 & -31.5 & -32.4 & $-{ }^{a}$ & - & - \\
\hline LTL & 1.00 & -16.1 & -41.8 & -48.1 & -15.9 & -38.9 & -43.3 & -20.5 & -44.3 & -44.7 \\
\hline MEI & 0.95 & -19.3 & -45.9 & -49.8 & -18.6 & -42.8 & -45.5 & -23.5 & -48.0 & -45.9 \\
\hline AET & 0.83 & -18.4 & -42.9 & -46.0 & -19.7 & -42.1 & -42.0 & -24.5 & -47.3 & -42.8 \\
\hline DON & 0.82 & -20.2 & -44.4 & -45.3 & -21.3 & -43.0 & -40.7 & - & - & - \\
\hline AFR & 0.77 & -18.3 & -46.5 & -52.9 & -20.3 & -46.1 & -48.3 & - & - & - \\
\hline MAZ & 0.74 & -18.5 & -49.6 & -58.5 & -19.8 & -48.9 & -54.7 & -25.3 & -54.9 & -55.5 \\
\hline CFI & 0.74 & -25.3 & -55.8 & -57.1 & -25.7 & -54.6 & -54.3 & - & - & - \\
\hline AFI & 0.73 & -24.5 & -54.0 & -55.3 & -25.4 & -52.9 & -51.6 & -31.4 & -59.4 & -52.6 \\
\hline GME & 0.70 & -18.8 & -49.0 & -56.5 & -19.6 & -47.6 & -52.5 & - & - & - \\
\hline OFF & 0.68 & -22.1 & -56.1 & -63.8 & -19.1 & -52.1 & -62.0 & - & - & - \\
\hline $\mathrm{CON}$ & 0.66 & -22.2 & -57.6 & -66.3 & -16.8 & -51.9 & -65.9 & - & - & - \\
\hline MOR & 0.64 & -23.2 & -58.8 & -66.7 & -17.8 & -53.7 & -67.2 & -24.9 & -61.6 & -68.9 \\
\hline SSZ-31 & 0.64 & -26.2 & -61.1 & -65.5 & -17.5 & -52.7 & -65.9 & - & - & - \\
\hline BEA & 0.64 & -24.3 & -55.1 & -57.8 & -14.1 & -46.8 & -61.3 & -23.8 & -56.7 & -61.7 \\
\hline SFE & 0.64 & -22.9 & -59.9 & -69.3 & -11.2 & -50.9 & -74.6 & - & - & - \\
\hline VET & 0.59 & -25.9 & -66.2 & -75.5 & -12.9 & -56.6 & -82.0 & - & - & - \\
\hline MTW & 0.58 & -27.2 & -69.3 & -78.9 & -3.9 & -49.7 & -86.1 & - & - & - \\
\hline
\end{tabular}

a Not determined.

This would imply that simulations based on an assumption of low loading are largely irrelevant.

The importance of the intermolecular entropy effects appears to scale with pore size. One can distinguish five basic categories:

The first category comprises sieve structures with pores no more than $0.6 \mathrm{~nm}$ across (such as TON-, MTT-type zeolites). As discussed elsewhere [16], these sieves repulse paraffins with proximate methyl groups so strongly that they do not adsorb significant amounts at any pressure, and strongly prefer linear paraffins to branched paraffins.

The second category comprises sieves with pores with a diameter in the 0.60-0.70-nm range (such as MOR-, MTW-,

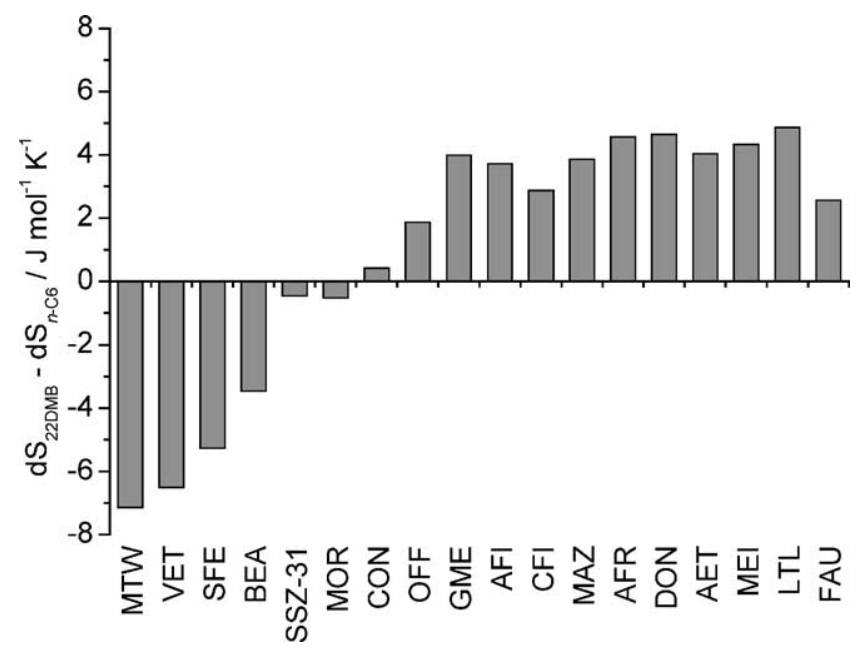

Fig. 3. Difference in adsorption entropy between $22 \mathrm{DMB}$ and $n-\mathrm{C}_{6}$ as calculated by CBMC. The structures are listed in order of increasing pore size.
SSZ-31-, and BEA-type zeolites). MOR-type zeolites afford a particularly nice example (Fig. 6). At low loading, zeoliteadsorbent interactions dominate, and the isomer with the lowest adsorption enthalpy, $n-\mathrm{C}_{6}$, is preferred (Table 1 , Fig. 2). At high loading, differences in packing efficiency change the preference toward branched isomers (Fig. 6), because these isomers are shorter so that more of them can stack into a single file [24,48] while retaining a larger number of conformations than the straightened-out linear isomers (Fig. 7).

The third category comprises tubular $0.70-0.75$-nm pore structures (AFI-, CFI-, MAZ-, and AFR-type sieves). These have no preference for $22 \mathrm{DMB}$ or $n-\mathrm{C}_{6}$ at low loading

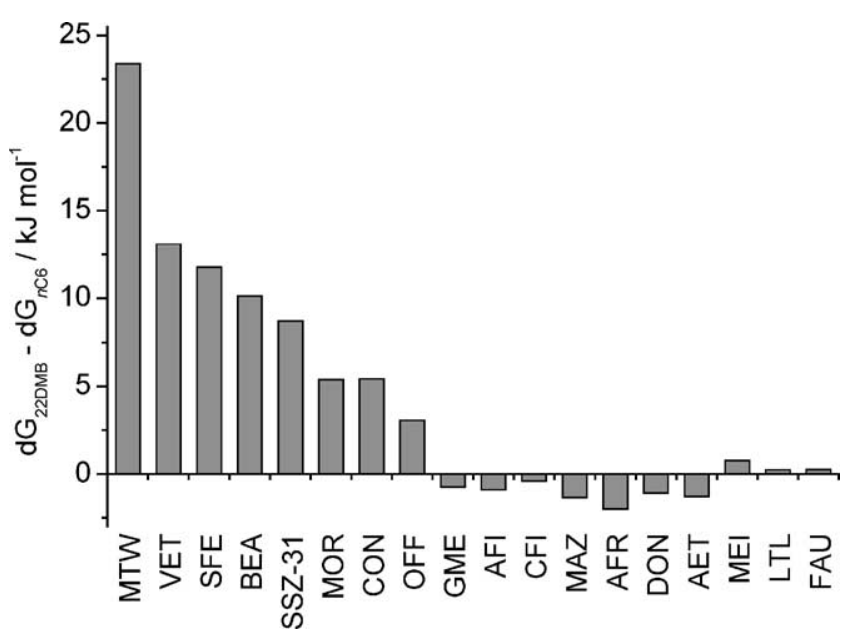

Fig. 4. Difference in Gibbs free energy of adsorption between 22DMB and $n-\mathrm{C}_{6}$ as calculated by CBMC. The structures are listed in order of increasing pore size. 


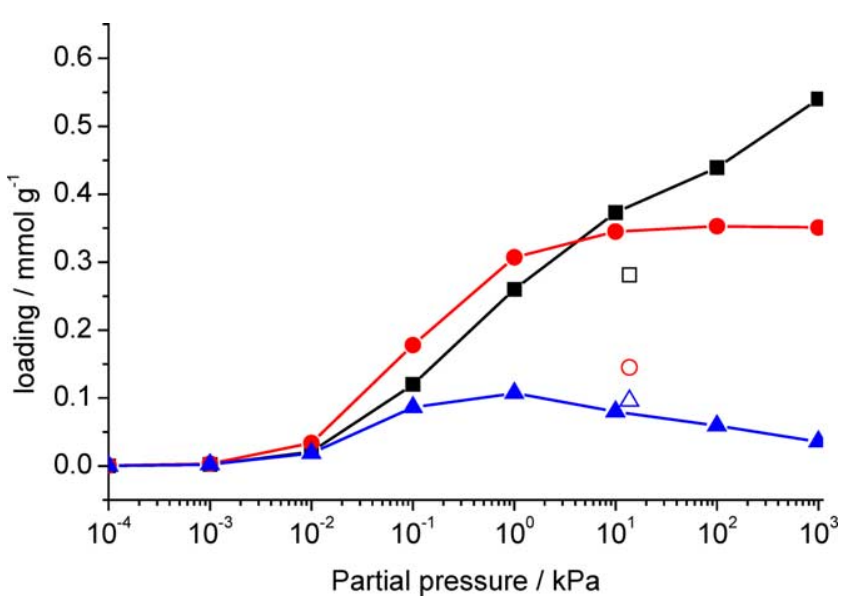

Fig. 5. Comparison of simulated adsorption isotherm of an equimolar mixture of 22DMB (-口-), 3MP (--), and $n-\mathrm{C} 6\left(-\boldsymbol{\Delta}_{-}\right)$with the experimental values of $22 \mathrm{DMB}(\square), 3 \mathrm{MP}(\bigcirc)$, and $n-\mathrm{C}_{6}(\triangle)$.

(Fig. 4), but prefer to adsorb the shortest, most branched isomer at high loading (Fig. 5). A publication that suggested that AFI's preference for 22DMB would already show up at low loading [37] discusses experiments that were done at too high a pressure and too low a temperature $\left(10^{-3} \mathrm{kPa}\right.$, $303-333 \mathrm{~K}$, as compared to $\ll 10^{-3} \mathrm{kPa}, 403 \mathrm{~K}$, Fig. 5) to actually approach low loading.

The fourth category comprises sieves with pores in the $0.80 \mathrm{~nm}$ range (DON- and AET-type sieves). As with the previous two categories, these sieves adsorb $\mathrm{C}_{6}$ mostly in a single file, but the void volume is now so large that it allows $n-\mathrm{C}_{6}$ to adsorb in many different configurations, from curled-up to stretched nearly perpendicular to the pore axis (Fig. 7). This allows the number of conformations and the effective length of $n-\mathrm{C}_{6}$ to converge toward that of 22DMB. The preference of adsorbing 22DMB rather than $n-\mathrm{C}_{6}$ decreases accordingly (cf. $\delta \Delta G_{14} \mathrm{kPa} 22-n$ in Table 1).
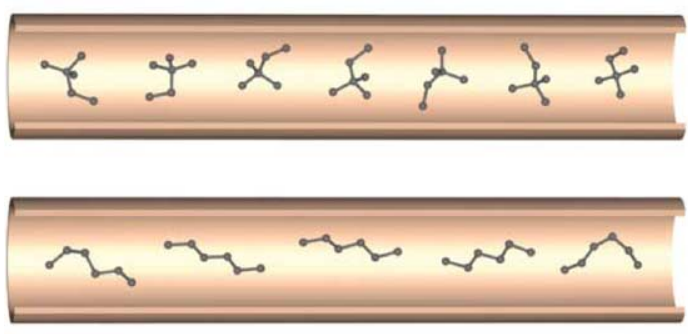

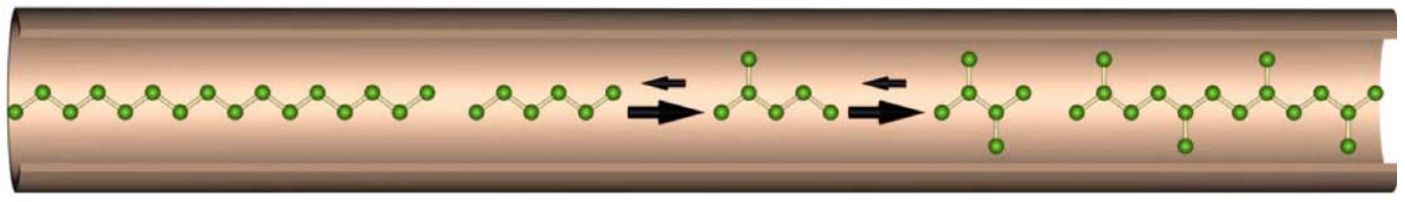

Fig. 7. The top four tubes represent typical conformations of linear and branched $\mathrm{C}_{6}$ isomers adsorbed in AFI (left) and DON (right). In the smaller pore of AFI, the effective size difference between linear and branched isomers is maximized. In the wider pore of DON, the linear isomer can adapt a wider range of conformations, diminishing the entropy effect caused by packing. The bottom tube depicts schematically the experimental conditions, when the pores are fully loaded. Under these conditions entropy effects caused by alkane-alkane interactions become important, driving the isomerization reaction toward the most compact isomer.

Fig. 6. Loading, $L(\mathrm{mmol} / \mathrm{g})$ of MOR-type silica in equilibrium with an equimolar mixture of $22 \mathrm{DMB}(\mathbf{\square})$ and $n-\mathrm{C}_{6}(\bullet)$ at pressure $p(\mathrm{kPa})$ and $403 \mathrm{~K}$.

The fifth category comprises sieves with pores in the order of $1.0 \mathrm{~nm}$ and larger (e.g., FAU-, LTL-, MEI-, VFItype sieves). These pores accommodate more than a single file of molecules, so that differences in the enthalpy of condensation start to contribute, and $n-\mathrm{C}_{6}$ becomes preferred over 22DMB because the former has the highest boiling point (Table 1).

Remarkably, the differences in Gibbs free energy between $22 \mathrm{DMB}$ and $n-\mathrm{C}_{6}$ calculated from simulated binary isotherms at $14 \mathrm{kPa}, \delta \Delta G_{14} \mathrm{kPa} 22-n(\mathrm{~kJ} / \mathrm{mol})$, correlate quite well with the differences in Gibbs free energy of adsorption determined from measured ternary isotherms at $14 \mathrm{kPa}$, $\delta \Delta G_{14 \mathrm{kPa} 22-n}(\mathrm{~kJ} / \mathrm{mol})$ (Table 1). MTW-type zeolite is the exception. Reasons for the discrepancy between the simulated and the experimental data on the MTW-type zeolite include exterior surface effects and a high sensitivity of the modeling parameters to tightly fitting molecules [16]. The
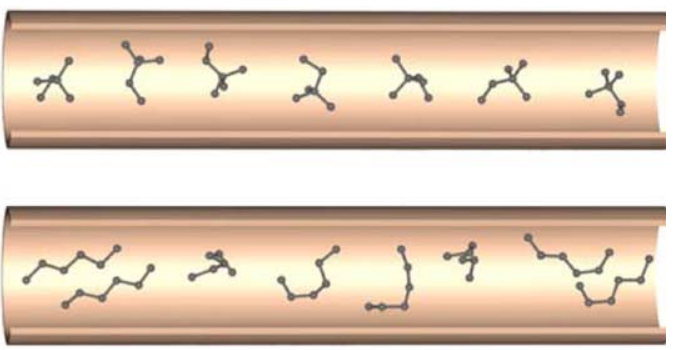
close similarity of data obtained from measured and simulated isotherms indicates that the relative preference of structures for adsorbing the shorter 22DMB rather than the longer $n-\mathrm{C}_{6}$ predominantly reflects a difference in adsorption entropy (packing efficiency) peculiar to adsorption in a one-dimensional pore. As this type of adsorption entropy is a result of intermolecular interactions, it does not become apparent until relatively high loading. It now remains to be sorted out how the adsorption entropy found at high loading can affect shape selectivity.

\subsection{Catalysis: paraffin hydroconversion mechanism}

Before addressing how structures can affect the paraffin hydroconversion selectivity of both complex industrial feeds [29] and $n-\mathrm{C}_{16},[9,10]$ it is useful to discuss the current model for paraffin hydroconversion. The hydroconversion of linear paraffins consists of a series of consecutive hydroisomerization reactions that steadily increase the degree of branching. Although all hydroisomerization reactions strive toward chemical equilibrium, equilibrium is never achieved due to an increasing chance of irreversible hydrocracking reactions with increasing degree of branching [26]. When long paraffins like $n-\mathrm{C}_{16}$ hydrocrack early in the chain of hydroisomerization reactions they yield $n-\mathrm{C}_{6}$ when they hydrocrack late, they yield DMB $[49,50]$. Therefore, the ratio between the initially formed DMB and $n-\mathrm{C}_{6}$ is a measure for the extent to which $n-\mathrm{C}_{16}$ hydroisomerizes before it hydrocracks, and, thereby, for the rate of the hydroisomerization reactions relative to that of the hydrocracking reactions. In practice, measuring the ratio between initially formed DMB and $n-\mathrm{C}_{6}$ is impeded by consecutive hydroisomerization reactions that drive the initially produced $\mathrm{C}_{6}$ fraction toward its intracrystalline chemical equilibrium [24]. Extensive consecutive hydroisomerization reactions are likely at the $\sim 99 \% n-\mathrm{C}_{16}$ hydroconversion at which Santilli et al. report their data.

\subsection{Catalysis: impact of $C_{16}$ adsorption thermodynamics}

Santilli et al. attributed the variation of the branching hydroisomerization rate with zeolite structure (Fig. 1) to a variation in the stabilization of the transition state for forming branched $\mathrm{C}_{16}$ paraffins $[9,10]$. Such a kinetic explanation for differences in hydroisomerization rate was favored, because it was assumed that the paraffins inside molecular sieves would all approach the same (gas phase) equilibrium $[9,10]$. In addition, the computational techniques available in the early 1990s did not allow Santilli et al. to perform the calculations for the systems of interest (long-chain hydrocarbons), under the conditions of interest (high pressure). To make the computations feasible they had to assume that the behavior of the short-chain paraffins at infinite dilution is representative.

Nowadays, long-chain hydrocarbons under reaction conditions are amenable to molecular simulations, as illus-

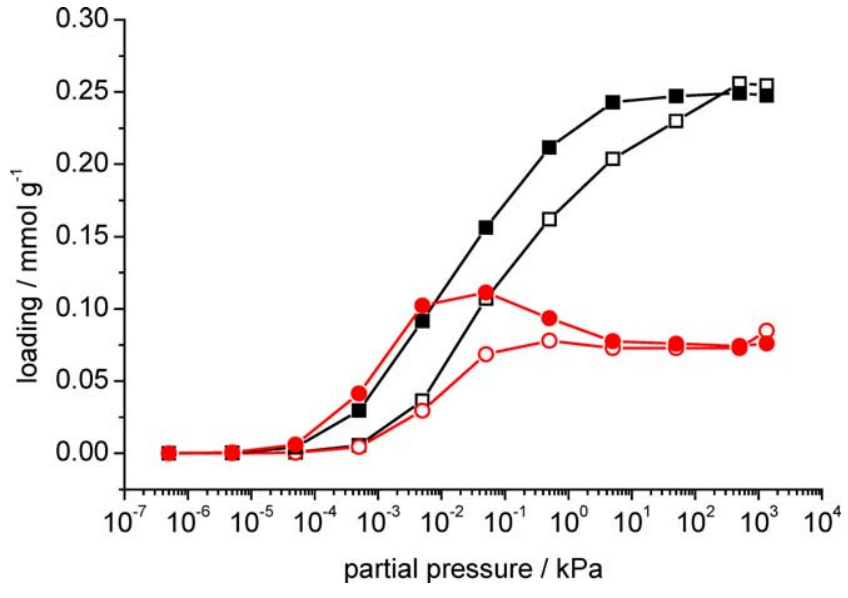

Fig. 8. Loading, L (mmol/g), of AFI- (closed symbols) and DON-type silica (open symbols) in equilibrium with an equimolar mixture of 2,5,8,11-teM-C ${ }_{12}(\boldsymbol{\square})$ and $n-\mathrm{C}_{16}(\mathbf{)})$ at pressure $P(\mathrm{kPa})$ and $577 \mathrm{~K}$. Reaction conditions of Santilli et al. [10] are $3 \times 10^{3} \mathrm{kPa} \mathrm{C}_{16}$ at $577 \mathrm{~K}$.

trated by the simulated binary isotherm of equal amounts of 2,5,8,11-tetramethyldodecane (a teM-C 12 ) and $n-\mathrm{C}_{16}$ at $577 \mathrm{~K}$ (Fig. 8). It shows that AFI- and DON-type pores are fully saturated with reactant under reaction conditions $\left(3 \times 10^{3} \mathrm{kPa} \mathrm{C}_{16}, 577 \mathrm{~K}\right.$ [10]). Similar simulations show that also pores as large as the 1.2-nm-wide FAU-type supercages are fully saturated with reactant under these conditions.

When pores are at saturation loading, molecular exchange between gas phase and adsorbed phase will be too slow to bring the adsorbed phase to gas-phase chemical equilibrium $[22,23,25,26]$. Instead, the adsorbed phase will exhibit an intracrystalline chemical equilibrium as defined by the intracrystalline Gibbs free energies of formation of the various isomers [21,24]. The intracrystalline chemical equilibrium tends to favor the formation of isomers with the lowest Gibbs free energy of adsorption [21,24], because isomers of the same carbon number usually have a comparable Gibbs free energy of formation in the gas phase [51]. Therefore the lowest Gibbs free energy of adsorption tends to correspond to the lowest Gibbs free energy of formation in the adsorbed phase $[17,21,24]$.

The binary isotherms indicate that AFI- and DON-type zeolites equally prefer adsorbing and forming branched rather than linear $\mathrm{C}_{16}$ under reaction conditions $(577 \mathrm{~K}$, $3 \times 10^{3} \mathrm{kPa}$, Fig. 8). $n-\mathrm{C}_{16}$ is that much longer than $n-\mathrm{C}_{6}$ that it cannot curl up or reorient itself the way $n-\mathrm{C}_{6}$ can in DON-type pores, and thereby reduce its effective length. $n-\mathrm{C}_{16}$ inside DON-type pores remains stretched out, to the extent that its length approaches that of $n-\mathrm{C}_{16}$ in a AFItype pore. With the disappearance of differences in effective length of the $n$-paraffin, also the difference in preference between DON- and AFI-type pores for branched rather than linear paraffins vanishes when going from $\mathrm{C}_{6}$ to $\mathrm{C}_{16}$.

Our simulations clearly indicate that none of the key assumptions underlying the mechanism of inverse shape selectivity hold. The pores are not nearly empty, but saturated with reactant under reaction conditions. The hydroisomerization reactions do not approach gas phase but adsorbed 
phase chemical equilibrium. One cannot extrapolate the thermodynamic stabilization of adsorbed branched $\mathrm{C}_{6}$ isomers to that of adsorbed branched $\mathrm{C}_{16}$ isomers.

\subsection{Catalysis: impact of $C_{6}$ adsorption thermodynamics}

An alternative mechanism can be formulated if one assumes that the $\mathrm{C}_{6}$ hydrocracking products formed initially will continue to hydroisomerize as long as more slowly diffusing $\mathrm{C}_{16}$ molecules keep them trapped inside the pores. As long as it remains trapped, $\mathrm{C}_{6}$ will hydroisomerize toward the chemical equilibrium inside the pores. Once desorbed, $\mathrm{C}_{6}$ will fail to compete with $\mathrm{C}_{16}$ for readsorption, so that the $\mathrm{C}_{6}$ isomers will not continue to hydroisomerize to reach a gas-phase chemical equilibrium distribution (Fig. 7).

Although Santilli et al. assumed that $\mathrm{C}_{6}$ hydroisomerization would be negligible [10], we would expect extensive $\mathrm{C}_{6}$ hydroisomerization, for the reaction temperature is $577 \mathrm{~K}$ [10], which is significantly above the threshold temperature for $\mathrm{C}_{6}$ hydroisomerization. Typically these reactions are carried out at $520 \mathrm{~K}$ or higher $[52,53]$.

Santilli et al. argued that the 9 times higher yield of $23 \mathrm{DMB}$ as compared to $22 \mathrm{DMB}$ is far from gas-phase chemical equilibrium and that, therefore, consecutive $\mathrm{C}_{6}$ hydroisomerization was precluded [10]. We would argue that the high 23DMB yield does not preclude consecutive $\mathrm{C}_{6}$ hydroisomerization, because $23 \mathrm{DMB}$ is kinetically favored to 22DMB [54], and so is the first DMB to form. At the high hydrocarbon pressures used [10], 23DMB is also thermodynamically favored to 22DMB (Table 4). This thermodynamic preference is in agreement with the majority of the adsorption data [10,34]. The lower Gibbs free energy of formation and adsorption of 23DMB relates to a smaller loss of entropy upon adsorption, because the vicinal methyl groups in 23DMB allow for a larger number of conformations than the geminal methyl groups in
22DMB. Because of its entropic origin, the intracrystalline thermodynamic driver for 23DMB rather than 22DMB under the conditions of simulation $\left(5 \times 10^{2} \mathrm{kPa}, 403 \mathrm{~K}\right)$ will be even higher at the higher pressure and temperature under reaction conditions $\left(3 \times 10^{3} \mathrm{kPa}\right.$ hydrocarbon, $\left.577 \mathrm{~K}\right)$. By contrast, gas-phase thermodynamics would drive toward 22DMB rather than 23DMB formation [51,54]. Thus, the predominance of $23 \mathrm{DMB}$ in the DMB fraction is entirely consistent with hydroisomerization reactions of the $\mathrm{C}_{6}$ hydrocracking products toward the compound with the lowest intracrystalline Gibbs free energy of formation.

The strongest support for the predominant influence of the intracrystalline chemical thermodynamics on the $\mathrm{C}_{6}$ yield structure is that the simulated adsorption thermodynamics affords a quantitative link between the $\mathrm{C}_{6}$ adsorption thermodynamics and the $\mathrm{C}_{6}$ yield structure in $n$ - $\mathrm{C}_{16}$ hydroconversion (Table 4, Fig. 9). With the assumption that for all catalysts the $\mathrm{C}_{6}$ hydroisomerization proceeds to a comparable percentage of their respective intracrystalline chemical equilibrium, $\delta \Delta G_{\text {catal }}(\mathrm{kJ} / \mathrm{mol})$ should represent the difference in free energy of formation between 22DMB or $23 \mathrm{DMB}$ and $n-\mathrm{C}_{6}$ inside the sieves. It turns out that there is a linear relationship between this difference in Gibbs free energy of formation and the simulated differences in Gibbs free energy of adsorption (either under adsorption conditions $(14 \mathrm{kPa}, 403 \mathrm{~K})$ or under reaction conditions $\left(3 \times 10^{3} \mathrm{kPa}\right.$, $577 \mathrm{~K})$ ). The deviation of the CFI-type zeolite sample from this Gibbs free energy correlation is probably related to the exceptionally high temperature required to achieve $70 \%$ hydrocracking activity on the single CFI-type sample that has been evaluated $[55,56]$. If CFI is excluded, the variation in the differences in free energy of adsorption between DMB and $n-\mathrm{C}_{6}$ explains $90 \%$ of the variation in the differences in the free energy of formation (i.e., the correlation coefficient is 0.90). This linear correlation between the free energy of formation and of adsorption of DMB and $n-\mathrm{C}_{6}$ is illustrated

Table 4

$\delta \Delta G_{\text {catal }}(\mathrm{kJ} / \mathrm{mol})$ corresponds to the difference in Gibbs free energy of formation between teM- $\mathrm{C}_{12}$ and dM- $\mathrm{C}_{14}$ at $577 \mathrm{~K}[10], \delta \Delta G_{\mathrm{ads}} 22-n(\mathrm{~kJ} / \mathrm{mol})$ is the difference in Gibbs free energy of adsorption between $22 \mathrm{DMB}$ and $n-\mathrm{C}_{6}$ determined from a measured ternary isotherm, at $403 \mathrm{~K}$ and $14 \mathrm{kPa} \mathrm{C}_{6}$; $\delta \Delta G_{500 \mathrm{kPa} 22-n}(\mathrm{~kJ} / \mathrm{mol})$ and $\delta \Delta G_{500 \mathrm{kPa} 23-n}(\mathrm{~kJ} / \mathrm{mol})$ are the differences in Gibbs free energy of adsorption between 22DMB or 23DMB and $n-\mathrm{C}_{6}$ determined from a simulated binary isotherm at $403 \mathrm{~K}$ and $500 \mathrm{kPa}, \delta \Delta G_{3000 \mathrm{kPa} 22-n}$ and $\delta \Delta G_{3000 \mathrm{kPa} 23-n}$ are the same but determined at $577 \mathrm{~K}, 3 \times 10^{3} \mathrm{kPa}$

\begin{tabular}{|c|c|c|c|c|c|c|c|}
\hline $\begin{array}{l}\text { Void } \\
\text { category }\end{array}$ & $\begin{array}{l}\text { Structure } \\
\text { code }\end{array}$ & $\begin{array}{l}\delta \Delta G_{\text {catal }} \\
(\mathrm{kJ} / \mathrm{mol})\end{array}$ & $\begin{array}{c}\delta \Delta G_{\text {ads } 22-n} \\
(\mathrm{~kJ} / \mathrm{mol})\end{array}$ & $\begin{array}{c}\delta \Delta G_{500 \mathrm{kPa} 22-n} \\
(\mathrm{~kJ} / \mathrm{mol})\end{array}$ & $\begin{array}{c}\delta \Delta G_{500 \mathrm{kPa} 23-n} \\
(\mathrm{~kJ} / \mathrm{mol})\end{array}$ & $\begin{array}{c}\delta \Delta G_{3000 \mathrm{kPa} 22-n} \\
(\mathrm{~kJ} / \mathrm{mol})\end{array}$ & $\begin{array}{c}\delta \Delta G_{3000 \mathrm{kPa} 23-n} \\
(\mathrm{~kJ} / \mathrm{mol})\end{array}$ \\
\hline $\mathrm{V} 0.9-1.0 \mathrm{~nm}$ & LTL & 8.6 & 3.9 & 7.1 & 0.8 & 3.2 & -1.8 \\
\hline $\mathrm{V} 0.9-1.0 \mathrm{~nm}$ & MEI & n.a. ${ }^{a}$ & n.a. & 6.3 & 2.6 & - & - \\
\hline $\mathrm{V} 0.9-1.0 \mathrm{~nm}$ & FAU & 10.0 & 1.3 & 4.0 & -1.8 & 1.0 & -3.2 \\
\hline $\mathrm{IV} \sim 0.8 \mathrm{~nm}$ & DON & 7.6 & n.a. & 2.5 & -4.2 & -2.8 & -8.1 \\
\hline $\mathrm{IV} \sim 0.8 \mathrm{~nm}$ & AET & n.a. & n.a. & 0.3 & -4.9 & - & - \\
\hline III $0.70-0.75 \mathrm{~nm}$ & MAZ & -0.4 & n.a. & -8.4 & -14.9 & -6.3 & -13.4 \\
\hline III $0.70-0.75 \mathrm{~nm}$ & $\mathrm{AFI}$ & 0.2 & -4.8 & -8.0 & -16.0 & -6.5 & -14.2 \\
\hline III $0.70-0.75 \mathrm{~nm}$ & CFI & 5.3 & n.a. & -5.6 & -17.3 & - & - \\
\hline III $0.70-0.75 \mathrm{~nm}$ & AFR & n.a. & n.a. & -2.9 & -8.1 & - & - \\
\hline II $0.60-0.70 \mathrm{~nm}$ & MOR & 2.6 & -0.9 & -2.2 & -10.6 & 0.2 & -7.4 \\
\hline II $0.60-0.70 \mathrm{~nm}$ & SSZ-31 & 4.9 & n.a. & 1.6 & -9.8 & 4.6 & -8.9 \\
\hline II $0.60-0.70 \mathrm{~nm}$ & BEA & 6.0 & 3.5 & 3.5 & -6.4 & 6.5 & -3.7 \\
\hline II $0.60-0.70 \mathrm{~nm}$ & MTW & 12.1 & 7.2 & 12.5 & -1.7 & 19.3 & 3.5 \\
\hline
\end{tabular}

a n.a., not available. 


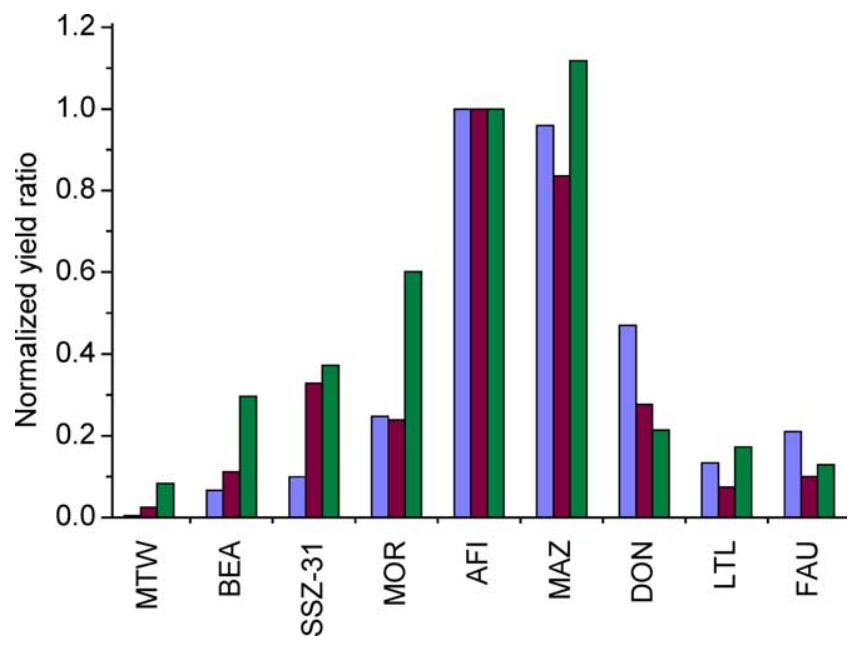

Fig. 9. Experimental and simulated normalized $\mathrm{DMB} / n-\mathrm{C}_{6}$ yield ratios for various zeolite structures. The ratios were normalized with respect to the AFI-type zeolite. The calculated ratios were obtained from simulated adsorption isotherms of equimolar mixtures of $22 \mathrm{DMB} / n-\mathrm{C}_{6}$ (left, light gray bar) and $23 \mathrm{DMB} / n-\mathrm{C}_{6}$ (middle, dark gray bar) under experimental conditions ( $T=577 \mathrm{~K}, P=3000 \mathrm{kPa}$ ). The experimental ratios (right bar) were taken from $n-\mathrm{C}_{16}$ hydroconversion experiments $[10,55]$.

by a good match between the $\mathrm{DMB} / n-\mathrm{C}_{6}$ yield and the simulated adsorption ratios in the traditional bell-shaped curve in Fig. 9. The measured differences in free energy of adsorption at $14 \mathrm{kPa}$ follow pretty much the same correlation as the simulated values at saturation loading (Table 4). The good correlation between the differences in the Gibbs free energy of adsorption and of formation of $\mathrm{C}_{6}$ isomers corroborates the suggestion that the intracrystalline thermodynamic equilibrium determines the direction of the hydroisomerization of the $\mathrm{C}_{6}$ isomers that are formed initially in $n-\mathrm{C}_{16}$ hydroconversion.

Previously, we have shown how pores selectively adsorb and produce molecules to the extent that they have a shape commensurate with that of the pore $[16,17,21]$. When the shapes are more commensurate, Van der Waals interactions between the pore walls and the adsorbate decrease the adsorption enthalpy and, thereby, the Gibbs free energy of adsorption and formation. It has now been found that pores can also favor the adsorption and formation of molecules because they are more compact, lose less entropy upon adsorption, and, thereby, have a lower Gibbs free energy of adsorption and formation.

The shape-selective redirection of the hydroisomerization reactions commensurate with the adsorption-induced shift in the Gibbs free energy of formation of reactants and products is a novel form of shape selectivity. This shape-selective change in reaction kinetics is not a form of transition-state shape selectivity, for it does not require an alteration of the Gibbs free energy of formation of any transition state. In light of the above analysis, the term inverse shape selectivity loses much of its relevance. Inverse shape selectivity was defined as the selective acceleration of the formation of bulky products, so as to contrast with regular shape selec- tivity, which was defined as the selective deceleration of the formation of bulky products [9]. We would argue that the compatibility between adsorbate and adsorbent defines what are bulky and what are compact molecules. DMB is more bulky then $n-\mathrm{C}_{6}$ in highly constrained MTW-type pores (reflected by DMB's higher adsorption enthalpy), whereas the inverse is true for AFI-like pores at high pressure (reflected by DMB's higher adsorption entropy). According to this definition, the preference of MTW-zeolites for adsorbing and forming $n-\mathrm{C}_{6}$ rather than DMB and the inverse preference of AFI-like zeolites are both examples of regular-not inverse-shape selectivity.

\section{Conclusions}

Molecular simulations show that differences in the Gibbs free energy of adsorption explain differences in paraffin hydroisomerization selectivity between catalysts. The important aspect of this work is that this selectivity can only be explained if we consider the zeolite to be fully saturated with reacting molecules. These saturated pores trap paraffins long enough to allow them to equilibrate toward the intracrystalline chemical equilibrium distribution. Pores less than $\sim 0.70 \mathrm{~nm}$ across equilibrate less toward branched paraffins than larger pores, because they repulse branched paraffins causing an increase in enthalpy of formation. This increase offsets their higher entropy of formation as a result of their better stacking efficiency. Pores $0.70-0.75 \mathrm{~nm}$ across are optimal for forming branched rather than linear paraffins, because they are large enough not to repulse the branched paraffins, and, thereby, maximize the effect of the better stacking efficiency of the shorter, branched paraffins. In larger pores linear $\mathrm{C}_{6}$ paraffins can curl up, so that the differences in stacking efficiency between branched and linear paraffins disappear. This effect is markedly reduced for $\mathrm{C}_{16}$ paraffins. When pores approach $1.0 \mathrm{~nm}$, condensation effects start to add in, and further reduce the preference for lower boiling branched isomers instead of higher boiling linear isomers. These entropy (stacking) effects only occur at high loadings, in which adsorbate-adsorbate interactions are important. This thermodynamic explanation for the high branched-paraffin yield in $n-\mathrm{C}_{16}$ hydroconversion is more rigorous than earlier explanations invoking (inverse) transition-state shape selectivity involving adsorbate-zeolite interactions only.

The link between adsorption thermodynamics and catalytic activity is well established [12,57-63]. The link between the Gibbs free energy of adsorption and shape selectivity has also been observed before [17,21], but only with respect to a lower adsorption enthalpy when molecular and pore shapes are commensurate. To the best of our knowledge, this is the first instance of shape-selective adsorption and production is due to higher (i.e., less negative) adsorption entropy and a concomitantly lower Gibbs free energy of formation in the adsorbed phase. It is probably not the 
last instance, e.g., kinetic data on aromatics hydroconversion $[64,65]$ also seem to indicate that adsorption entropy may play a significant role in the selectivity in these types of conversions. Clearly adsorption entropy not only affects the activity [61-63], but also the selectivity of many zeolitecatalyzed conversions.

\section{Acknowledgments}

These investigations are supported in part by the Netherlands Research Council for Chemical Sciences (CW) with financial aid from the Netherlands Technology Foundation, by the Netherlands Organization for Scientific Research (NWO) through PIONIER, by ChevronTexaco, and by the Stichting Nationale Computer Faciliteiten (National Computing Facilities Foundation) through the use of the supercomputer facilities. We thank the European Commission for a Marie Curie Individual Research Fellowship (to S.C.). We thank C. Wilson, D.S. Santilli, C.H. Roemkens, A. Kuperman, T.V. Harris, and S.I. Zones, for their comments on our manuscript.

\section{References}

[1] P.M.M. Blauwhoff, J.W. Gosselink, E.P. Kieffer, S.T. Sie, W.H.J. Stork, in: J. Weitkamp, L. Puppe (Eds.), Catalysis and Zeolites, Springer, Berlin, 1999, pp. 437-538.

[2] K. Tanabe, W.F. Hölderlich, Appl. Catal. 181 (1999) 399-434.

[3] Ch. Marcilly, in: A. Galarneau, F. Di Renzo, F. Fajula, J. Vedrine (Eds.), Zeolites and Mesoporous Materials at the Dawn of the 21st Century, in: Stud. Surf. Sci. Catal., Vol. 135, Elsevier, Amsterdam, 2001, pp. 37-60.

[4] Ch. Baerlocher, W.M. Meier, D.H. Olson, Atlas of Zeolite Structure Types, 5th ed., Elsevier, Amsterdam, 2001, http://www.iza-structure.org/databases/ by Ch. Baerlocher, L.B. McCusker.

[5] J. Weitkamp, S. Ernst, L. Puppe, in: J. Weitkamp, L. Puppe (Eds.), Catalysis and Zeolites, Springer, Berlin, 1999, pp. 326-376.

[6] P.B. Weisz, Pure Appl. Chem. 52 (1980) 2091-2103.

[7] S.M. Csicsery, Zeolites 4 (1984) 202-213.

[8] R.A. Van Nordstrand, D.S. Santilli, S.I. Zones, in: W.H. Flank, Th.E. Whyte (Eds.), Perspectives in Molecular Sieve Science, in: ACS Symp. Ser., Vol. 368, Am. Chem. Society, Washington, 1988, pp. 236 245.

[9] R.A. Van Nordstrand, D.S. Santilli, S.I. Zones, in: M.L. Occelli, H.E. Robson (Eds.), Synthesis of Microporous Materials, in: Molecular Sieves, Vol. 1, Van Nostrand, New York, 1992, pp. 373-383.

[10] D.S. Santilli, T.V. Harris, S.I. Zones, Micropor. Mater. 1 (1993) 329 341.

[11] D.S. Santilli, S.I. Zones, Catal. Lett. 7 (1990) 383-387.

[12] E.G. Derouane, J. Mol. Catal. A 134 (1998) 29-45.

[13] W.O. Haag, in: J. Weitkamp, H.G. Karge, H. Pfeifer, W. Hölerich (Eds.), Zeolites and Related Microporous Materials: State of the Art 1994, in: Stud. Surf. Sci. Catal., Vol. 135, Elsevier, Amsterdam, 1994, pp. 1375-1394.

[14] J.A. Martens, W. Souverijns, W. Verrelst, R. Parton, G.F. Froment, P.A. Jacobs, Angew. Chem. Int. Ed. Eng. 34 (1995) 2528-2530.

[15] J.A. Martens, P.A. Jacobs, in: H. Van Bekkum, E.M. Flanigen, P.A. Jacobs, J.C. Jansen (Eds.), Introduction to Zeolite Science and Practice, 2nd ed., in: Stud. Surf. Sci. Catal., Vol. 137, Elsevier, Amsterdam, 2001, pp. 631-672.
[16] Th.L.M. Maesen, M. Schenk, T.J.H. Vlugt, J.P. De Jonge, B. Smit, J. Catal. 188 (1999) 403-412.

[17] M. Schenk, B. Smit, T.J.H. Vlugt, T.L.M. Maesen, Angew. Chem. Int. Ed. Eng. 40 (2001) 736-739.

[18] P. Raybaud, A. Patrigeon, H. Toulhoat, J. Catal. 197 (2001) 98-112.

[19] G. Sastre, A. Chica, A. Corma, J. Catal. 195 (2000) 227-236.

[20] M.C. Claude, G. Vanbutsele, J.A. Martens, J. Catal. 203 (2001) 213231.

[21] T.L.M. Maesen, M. Schenk, T.J.H. Vlugt, B. Smit, J. Catal. 203 (2001) 281-291.

[22] R.A. Van Santen, A. Van de Runstraat, R.J. Gelten, in: G.F. Froment, K.C. Waugh (Eds.), Dynamics of Surfaces and Reaction Kinetics in Heterogeneous Catalysis, in: Stud. Surf. Sci. Catal., Vol. 109, Elsevier, Amsterdam, 1997, pp. 61-77.

[23] A. Van de Runstraat, J.A. Kamp, P.J. Stobbelaar, J. Van Grondelle, S. Krijnen, R.A. Van Santen, J. Catal. 171 (1997) 77-84.

[24] M. Schenk, S. Calero, T.L.M. Maesen, L.L. Van Benthem, M.G. Verbeek, B. Smit, Angew. Chem. Int. Ed. Eng. 41 (14) (2002) 25002502.

[25] D. Schuring, A.P.J. Jansen, R.A. Van Santen, J. Phys. Chem. B 104 (2000) 941-948.

[26] G.F. Froment, Catal. Today 1 (1987) 455-473.

[27] N.Y. Chen, S.J. Lucki, E.B. Mower, J. Catal. 13 (1969) 329-332.

[28] R.L. Gorring, J. Catal. 31 (1973) 13-26.

[29] J.W. Ward, US patent 4,695,368, 1987.

[30] M.D. Macedonia, E.J. Maginn, Mol. Phys. 96 (1999) 1375-1390.

[31] T.J.H. Vlugt, R. Krishna, B. Smit, J. Phys. Chem. B 103 (1999) 11021118.

[32] S. Calero, B. Smit, R. Krishna, J. Catal. 202 (2001) 395-401.

[33] S. Calero, B. Smit, R. Krishna, Phys. Chem. Chem. Phys. 3 (2001) 4390-4398.

[34] B. McCulloch, J.R. Lansbarkis, S. Raghuram, R.S. Haizmann, US patent 5,107,052, 1992.

[35] S.B. McCullen, P.T. Reischman, D.H. Olson, Zeolites 13 (1993) 640644.

[36] F. Eder, J.A. Lercher, J. Phys. Chem. 100 (1996) 16460-16462.

[37] J.M. Guil, R. Guil-López, Perdigón-Melón, A. Corma, Micropor. Mesopor. Mater. 22 (1998) 269-279.

[38] B.L. Newalkar, R.V. Jasr, V. Kamath, S.G.T. Bhat, Adsorption 5 (1999) 345-357.

[39] A.G. Bezus, A.V. Kiselev, A.A. Lopatkin, P.Q. Du, J. Chem. Soc. Faraday Trans. II 74 (1978) 367-379.

[40] R.L. June, A.T. Bell, D.N. Theodorou, J. Phys. Chem. 96 (1992) 10511060.

[41] B. Smit, J.I. Siepmann, J. Phys. Chem. 98 (1994) 8442-8452.

[42] T. Maris, T.J.H. Vlugt, B. Smit, J. Phys. Chem. B 102 (1998) 71837189.

[43] R.F. Lobo, M. Tsapatsis, C.C. Freyhardt, I. Chan, C.-Y. Chen, S.I. Zones, M.E. Davis, J. Am. Chem. Soc. 119 (1997) 3732-3744.

[44] J.F. Denayer, W. Souverijns, P.A. Jacobs, J.A. Martens, G.V. Baron, J. Phys. Chem. B 102 (1998) 4588-4597.

[45] S.M. Babitz, B.A. Williams, J.T. Miller, R.Q. Snurr, W.O. Haag, H.H. Kung, Appl. Catal. A 179 (1999) 71-86.

[46] J. Jänchen, H. Stach, L. Uytterhoeven, W.J. Mortier, J. Phys. Chem. B 100 (1996) 12489-12493.

[47] F. Eder, M. Stockenhuber, J.A. Lercher, J. Phys. Chem. B 101 (1997) $5410-5414$.

[48] J. Talbot, AIChE J. 43 (1997) 2471-2479.

[49] J. Weitkamp, S. Ernst, Catal. Today 19 (1994) 107-150.

[50] J.A. Martens, P.A. Jacobs, in: J.B. Moffat (Ed.), Theoretical Aspects of Heterogeneous Catalysis, Van Nostrand Reinhold, New York, 1990, pp. 52-109.

[51] D.R. Stull, E.F. Westrum Jr., G.C. Sinke, The Chemical Thermodynamics of Organic Compounds, Krieger, Malabar, FL, 1987.

[52] H.W. Kouwenhoven, C.W. Van Zijll Langhout, Chem. Eng. Prog. 67 (1971) 65-70.

[53] A. Corma, J. Frontela, J. Lázaro, M. Pérez, Prepr.-Am. Chem. Soc. Div. Peet. Chem. 36 (1991) 833-840. 
[54] J.F. Allain, P. Magnoux, Ph. Schulz, M. Guisnet, Appl. Catal. 152 (1997) 221-235.

[55] M. Yoshikawa, P. Wagner, M. Lovallo, K. Tsuji, T. Takewaki, C.-Y. Chen, L.W. Beck, C. Jones, M. Tsapatsis, S.I. Zones, M. Davis, J. Phys. Chem. B 102 (1998) 7139-7147.

[56] T.V. Harris, personal communication.

[57] E.G. Derouane, J.M. Andre, A.A. Lucas, J. Catal. 110 (1988) 58-73.

[58] W.O. Haag, in: J. Weitkamp, H.G. Karge, H. Pfeifer, W. Hölderich (Eds.), Zeolites and Related Microporous Materials: State of the Art 1994, in: Stud. Surf. Sci. Catal., Vol. 84, Elsevier, Amsterdam, 1994, pp. 1375-1394.
[59] J.A. Lercher, K. Seshan, Curr. Opin. Solid State Mater. Sci. 2 (1997) $57-62$.

[60] J. Wei, Chem. Eng. Sci. 51 (1996) 2995-2999.

[61] A. Van de Runstraat, J. Van Grondelle, R.A. Van Santen, Ind. Eng. Chem. Res. 36 (1997) 3116-3125.

[62] G.C. Bond, M.A. Keane, H. Kral, J.A. Lercher, Catal. Rev. Sci. Eng. 42 (2000) 232-383.

[63] E. Roduner, H. Digler, J. Am. Chem. Soc. 123 (2001) 7717-7718.

[64] G. Mirth, J. Čejka, J.A. Lercher, J. Catal. 139 (1993) 24-33.

[65] A. Corma, F. Llopis, J.B. Monton, J. Catal. 140 (1993) 384-394. 